\title{
REVIEW
}

\section{Genetically altered mice, man and medicine}

\author{
Nirmala Bhogal \\ FRAME, Nottingham, United Kingdom
}

Received $6^{\text {th }}$ February 2008.

Revised $10^{\text {th }}$ March 2008.

Published on line $12^{\text {th }}$ March 2008.

\begin{abstract}
Summary
Several million genetically altered mice are used worldwide each year for research, toxicity testing, or simply to create or sustain mutant models. In fact, as our understanding of the genetic differences between mice and men improves, so does the drive to create mouse models of human disease and toxicity. However, while some models have proven to be useful and confer tangible benefits in terms of clinical management of disease, many others add little value to clinical medicine or human safety emphasising the need for a thorough investigation of the actual or future value of such models to human medicine.
\end{abstract}

Key words: disease - genetically altered - mouse - mutant - welfare

\section{INTRODUCTION}

The mouse is the most frequently used laboratory animal. Historically, mice were considered vermin and even today countries such as the US actively exclude mice from the legal protection afforded other laboratory mammals. If it is also considered that mice are relatively easy to breed and inexpensive to maintain in captivity and that most genetic engineering techniques have been perfected for mice, it is perhaps not surprising that research and testing in these animals outstrips that on any other mammalian species. Couple the latter with the fact mice have short life spans and produce large numbers of

\footnotetext{
$\triangle$ N. Bhogal, FRAME, Russell and Burch House, 96-98 North Sherwood Street, Nottingham NG1 4EE, UK

品 nirmala@frame.org.uk

魚 +441159584740

目 +441159503570
}

offspring, means they are suited for genetic experimentation and toxicity testing whilst avoiding issues with long term, post-experimental care. However, the biggest selling point for mouse models is the fact that the mouse (Mouse Genome Sequencing Consortium 2002) and human genomes (International Human Genome Sequencing Consortium 2001) are of similar sizes, apparently around 95\% syntenic and display reputedly high functional equivalence.

While the short life-spans of mice and their size are advantageous, these characteristics equally confound extrapolation of information from studies on mice to human disease and medicine. Equally, although the mouse and human genomes appear at first glance to be strikingly similar, since a single nucleotide difference can dramatically alter protein expression, trafficking, structure or function, the fact that mouse and human genes are on average only $85 \%$ similar is at best problematic and at worst leads to ill-informed assumptions about drug activity and safety.

These issues are explored further in the context of specific diseases to determine where genetically 
altered (GA) mouse models have and have not benefited the study of human disease and human medicine. Throughout this article, human genes are given in uppercase and italics and mouse homologues in lower case and italics.

\section{MOUSE MODELS OF SICKLE CELL ANAEMIA}

Sickle cell anaemia (SCA) is an inherited blood disorder that affects the shape, haemoglobin content, half-life and blood vessel traffic of red blood cells. The symptoms of SCA include pain and complications such as stroke that can currently be managed medically using a number of generic therapeutics. The prospects for developing gene therapies and enhancing stem cell therapies are being investigated in mouse models. The latter show greatest promise although, at present, problems with reprogramming stem-ness with oncogenic and retroviral DNA remain unresolved (Hanna et al. 2007).

Ordinarily, 95-98\% of the haemoglobin content is haemoglobin A, which is composed of two $\alpha$ and two $\beta$ chains with a smaller proportion of haemoglobin composed of two $\alpha$ with two $\delta$ chains (Haemoglobin A2) or two $\gamma$ chains (fetal haemoglobin). In SCA, the majority of red blood cells contain haemoglobin $S$, because of mutations in the $ß$ chain gene ( $\aleph^{s}$ mutations). Early mouse models of SCA were created by replacing the mouse haemoglobin genes ( $h b A$ and $h b B$ ) with the equivalent human genes $(H b A$ and $H b B)$ with $\beta^{s}$ mutations. Although expressing mainly haemoglobin S (Greaves et al. 1990), these mice displayed little red blood cell sickling that was increased in SAD mice that carried three point mutations, namely the $\beta^{s}$ Antilles ß23Ile and D Punjab ß121Gln mutations in the $H b B$ gene (Trudel et al. 1991). Although useful for examining the effects of potential anti-sickling agents, these mice do not display haemolytic anaemia that is seen in SCA humans.

The Berkeley mouse has deactivated mouse $h b A$ and $h b B$ genes and, instead, expresses the full complement of human SCA globin $\alpha$ and $ß$ genes, including the mutant $\beta^{\mathrm{s}}$ genes (genotype: Tg[Hu-miniLCR $\left.\left.\alpha 1^{\mathrm{g}} \gamma^{\mathrm{A}} \gamma \delta \aleph^{\mathrm{S}}\right] H b a^{\circ} / / \mathrm{Hba}^{\circ} \mathrm{Hbbo} / / \mathrm{Hbb}^{\mathrm{o}}\right)$. Even this model only displays some features of the human disease (Paszty et al. 1997). For instance, contrary to the increased red blood cell haemoglobin levels seen in patients, the Berkley mouse exhibits reduced red blood cell haemoglobin levels. This may be a result of the fact that mice express very low levels of fetal haemoglobin, a protein that protects against depleted haemoglobin levels in human SCA sufferers. The latter is linked to the different severities of SCA-related symptoms seen in patients. Together with the fact that red blood cell volumes are much smaller in mice than in humans, this presumably explains why Berkeley mice are prone to more severe SCA than many patients. Differences in the main site of haematopoiesis (the spleen in the Berkeley mouse and the bone-marrow in SCA patients) might also contribute to species differences since splenic hypertrophy is apparent in 1-6 month old mice, whereas in humans, initial hypertrophy is followed by almost total loss of spleen function (Manci et al. 2006). Despite these problems, studies in mouse SCA models have resulted in promising new therapies, including a new hemoglobin-based oxygen carrier (HBOC), HRC 101 (Hemosol in Shichor et al. 2007). This is because the same organs are affected in mice and humans, albeit to different extents, and because the therapeutic efficacies of HBOCs are largely dependent on ADME and being able to reach the target site.

\section{SPECIES DIFFERENCES ARISING FROM ALTERNATIVE PATHWAYS AND FUNCTIONAL NON-EQUIVALENCE: DIABETES AND CYSTIC FIBROSIS}

Human diabetes embraces a cluster of diseases characterised by an inability to regulate blood glucose levels. The link between obesity and the incidence of diabetes has spurred the use of some mouse models. However, it is clear that models such as the non-obese diabetic (NOD) mice, the product of selective breeding and which spontaneously develop insulin-dependent diabetes, can be used to decipher the complex pathways associated with the autoimmune component of type I diabetes. Indeed, there appears to be considerable similarity between the roles of the components of the major histocompatibility complex II and cytokines in the mouse model and human conditions (Wicker et al. 2005).

A species analogue of Diapep277 ${ }^{\mathrm{TM}}$ (DeveloGen, Germany) was first assessed in NOD mice. It was found to react with heat shock protein 60 on autoimmune T cells in NOD mice and, as a result, promote insulin secretion. The underlying mechanism is proposed to be a result of changes in the types of cytokines release from $\mathrm{T}$ cells from those that promote to those that counter inflammation (Elias et al. 1997, Ablamunits et al. 1998). According to the outcome of phase I and phase II clinical trials, 
Daipep277 ${ }^{\mathrm{TM}}$ promises to be the first peptide immunomodulatory therapeutic able to tackle the autoimmune problems presented by diabetes. The phase III clinical trials data are expected to be published later this year.

Other alternatives to insulin therapy, such as immune cell reprogramming therapies are being investigated in such mouse models. Should these restorative therapies become available, the need for long term use of insulin by certain patients might be dispensed with. However, the cost of such personalised medicines might be prohibitively expensive such that research into this area must be carefully appraised.

Maturity onset diabetes of the young (MODY) and adult type 2 diabetes are, likewise, multigenic disorders. As such, several GA mouse models have been used to studies on individual components of type 2 diabetes. However, functional non-equivalence between mice and humans creates problems with extrapolating between studies in mouse models to drug development and clinical medicine. For instance, loss-of-function mutations in the insulin receptor gene (resulting in poor insulin sensitivity), combined with the absence of a $\mathrm{K}_{\mathrm{ATP}}$ channel (which regulates insulin secretion), were insufficient to trigger diabetes in mice (Kanezaki et al. 2004) whereas equivalent mutations lead to diabetes in humans. Similarly, Sur1 knock-out mice carrying loss-of-function mutations in the SUR1 receptor for sulphonylureas that trigger closing of $\mathrm{K}_{\mathrm{ATP}}$ channels (thus reducing insulin secretion) are able to regulate insulin secretion via a second insulin regulatory mechanism that is not found in humans (Hiota et al. 2002). This limits the use of GA mice for developing therapeutics that target $\mathrm{K}_{\mathrm{ATP}}$ channel activity.

Functional non-equivalence is not restricted to diabetes. In the 1980s, cystic fibrosis (CF) was linked to mutations in the gene encoding the $\mathrm{CF}$ transmembrane conductance regulator (CFTR; Kerem et al. 1989) that normally facilitates chloride ion movement into and out of cells in the lungs and other organs. Recent evidence suggests that the so-called mouse CFTR is not a true homologue for the human protein (Rozmahel et al. 1997). This may go some way to explaining why studies in mouse models that attempt to capture features of CF have failed to generate any tangible improvements in medical management of this disease.

Around $70 \%$ of CF sufferers carry a single phenylalanine residue in the encoded protein but about 1300 frameshift and site-specific mutations in the human CFTR gene or the upstream promoter regions that have similar health consequences but with varied onset and severity. In humans, CFTR gene mutations result in the accumulation of thick, sticky mucus and other secretions that increase the individual's susceptibility to infections, impair cellular secretion and/or transport, and increase morbidity. Since CF is autosomal and recessive, two defective copies of the CFTR gene are needed before the disease manifests itself. Since not all CFTR gene mutations have the same phenotypic consequences, and the likelihood that a person would inherit identical mutant alleles is low whereas mouse models are created within homozygous mutations and deletions in mind. Furthermore, knock out mice such as cftr (-/-) mice do not develop mucus-congested lungs because mice but instead tend to die mainly as a result of gastrointestinal obstruction, which is not a feature of the human disease (Ameen et al. 2000). Pancreatic disorders and loss of fertility, seen in a high proportion of CF patients, are also rarely seen in cftr (-/-) mice.

It now seems CF is likely to be a multigenic disorder, dependent on the expression and function of other proteins (Kunzelmann et al. 2002). Hence, after decades of CFTR-related research newer, more useful model of airway mucus hypersecretion include a mouse model overexpressing an epithelial sodium ion channel under the control of an airway-specific promoter. This model exhibits increased sodium ion absorption and higher lung mucous concentrations, as seen in human CF lung disease (Mall et al. 2004). Perhaps such recent models hold greater potential for developing gene therapy and small molecule interventions but this remains to be seen.

\section{IMMUNODEFICIENCY MODELS}

GA mice models of infections caused by pathogens such as the human poliovirus (Boot et al. 2003) and used to develop and test vaccines and to bioassay pathogens, such as BSE (bovine spongiform encephalopathy; Jenkins and Combes 1999) are commonly engineered so that they possess humanised immune systems. The objective is to overcome problems with various immune cell niches that are significantly different in mice and humans. Models include severe combined immune deficiency (SCID) mice that carry two mutated copies of the SCID gene (SCID/SCID mice) lack T-cells and B-cells and SCID/beige mice that also lack natural killer activity. Total body irradiation of BALB/c mice to destroy the haematopoietic system, followed by its replacement by engrafting bone-marrow samples from SCID mice results in the generation of mouse models capable of mounting primary and secondary cellular and humoral immune responses specific to a number of infections, including hepatitis B, hepatitis $\mathrm{C}$ and HIV 
(Ayash-Rashkovsky et al. 2005). Such mouse models are additionally used as recipients for human tumour cell xenografts (Chang and Zhang 1995). For example, SCID mice also homozygous for the urokinase plasminogen activator (uPA-SCID mice) transplanted with primary human hepatocytes and infected with hepatitis B virus or hepatitis $C$ virus can be used as models of human hepatitis infection (Meuleman et al. 2005).

\section{MOUSE MODELS OF SENSORY FUNCTION}

A number of GA mice have been used to study sensorineural or conductive deafness. The Shaker1 mouse that contains mutations in myosin VIIA gene (Gibson et al. 1995) displays profound hearing loss, hyperactivity, head-tossing and circling activity. Mutations in the equivalent human myosin VIIA gene (MYO7A) lead to non-syndromic deafness and Usher's syndrome-associated deafness. However, half of all Usher's syndrome sufferers also exhibit retinitis pigmentosa which is not seen in even aged mice. This discordance may be because of the short lifespan of the mouse, which prevents the retina from receiving sufficient exposure to light to elicit pathological changes (El Amraoui et al. 1996).

Specific mouse models of autosomal dominant retinitis pigmentosa (RP), nevertheless, exist including rhodopsin knock-out rho (-/-) mice and transgenic mice that carry equivalent rhodopsin mutations to those related to human forms of the disorder (Sung et al. 1994). Although these models have proven informative about the visual process (Dalke and Graw 2005), differences between the organisation of the mouse and human visual systems, that are linked to the fact that mice are nocturnal animals whereas humans are not, complicate extrapolation of information from studies with these mouse models to human medicine. For instance, the retinas of mice possess fewer cone cells (for colour vision) but a higher density of rod cells (for night vision) than human retinas and lack fovea that affords visual acuity to humans. Mice also possess two, rather than three, visual pigments with one of the two pigments possessing absorption spectra overlap with rhodopsin such that this colour pigment can partly compensate for visual defects that result from loss-of-function mutations in rhodopsin in a way that is not possible in the human visual system. This may explain why mice carrying rhodopsin mutations do not develop severe retinopathies, as seen in humans (Jacobs et al. 1991). Nevertheless, research in mouse models has led to an initial assessment of stem cell therapies for RP and the realisation that the retina has regenerative capacity (MacLaren et al. 2006). Such treatments offer greater hope for patients who at present are almost exclusively reliant on the use of vitamin A to delay the onset of RP.

\section{MOUSE MODELS OF DEGENERATIVE DISEASES}

Duchenne Muscular Dystrophy (DMD) is characterised by early onset muscle degeneration and affects mainly male children. Not only is this not so in the DMD mouse model $d y / d y 2 j$ but also most of these mice exhibits muscle with rapid onset and die within 6 months. Even taking into account differences between the life-spans of mice (2-3 years) and humans (70-90 years), this is too rapid and, indeed, the muscle membrane appears to be more extensively damaged in $d y / d y 2 j$ mice than in DMD patients. Furthermore, human DMD is thought to be myogenic in origin while DMD in mice is believed to have a neurogenic origin. The $m d x$ mouse mimics the $\mathrm{X}$-linked recessive nature of human DMD and although this is an improvement over the $d y / d y 2 j$ model, this model fails to exhibit many of the features of the human disease including the fact that muscle necrosis in young $m d x$ mice is totally reversed and the mice are essentially disease-free by the age of 5 weeks (Daingain and Vrbova 1984). Studies on the dko mouse model that lacks expression of dystrophin and another muscle architectural protein, utrophin, not only revealed potential problems of using large DNA for dystrophin gene therapy (Gardner et al. 2006) but have also triggered efforts to develop alternative therapies. One such treatment option might include morphilino anti-sense oliionucleotides that reverse DMD in the $m d x$ mouse (Fletcher et al. 2007). These treatments are currently going through clinical trials in Europe.

Age-related neurodegenerative disorders, such as Alzheimer's disease (AD), are generally of slower onset than DMD. For instance, AD sufferers exhibit progressive loss of cognitive function and memory that is thought to relate to the development of amyloid plaques (APs) and neurofibrillary tangles (NFTs) in their brains and a loss of neuronal synaptic density and this can take several decades to manifest. Traditionally, mouse models were used to examine the roles of individual AD components, each displaying some, but not all, of the features of the human disease. The 3xTg-AD model captures all the main features of the human disease. Genes encoding human K670-N/M671-L APP (APPswe) and human P301L tau proteins were inserted into Thy1.2 cassettes, to drive CNS expression of mutant 
preselinin 1 and tau proteins and these constructs were injected into single cell embryos from PS1-KI mice containing the homozygous presenilin 1 mutation (PS1M146V). This presenilin 1 mutation predisposes mice to rapidly developing APs that also carry the amyloid precursor protein (APP) double mutant K670-N/M671-L (APPswe) gene (Holcomb et al. 1998). However, there were no signs of NFTs in the mice. By contrast, only NFTs were evident in a transgenic mouse model expressing the human P301L tau protein (Gotz et al. 2001). In this model neuron-specific CNS expression was achieved by placing the expression of P301L tau protein under the control of a neuron-specific mouse promoter. The 3xTg-AD mice captured features of both these models to exhibit progressive, brain region-specific neuropathological features characteristic of the human disease, with synaptic dysfunction preceding AP formation, which, in turn, preceded NFT formation. Furthermore, these mice are not behaviourally abnormal from birth thus a more suitable model for what is an age-related disease in humans. One of the most promising new treatments of AD, AF267B, was developed using this model and is currently in phase 1 investigative clinical trials in the US. Early results show the compound was well tolerated at tested doses in a group of young, healthy men although clinical efficacy remains to be established.

\section{TANGIBLE BENEFITS TO CLINICAL MEDICINE}

Mouse models, as all animal studies, should only be developed only when there is a realistic prospect for the development of new medical treatments and where alternative studies on lower order species and in vitro systems cannot provide the type of information that is needed to advance the field of research in question. In this respect, use of mouse models to study human congenital and developmental disorders must be carefully evaluated. Take for instance, cleft palate. It is the most common form of congenital bone dysmorphia in humans and develops within the first trimester of pregnancy. It is not only multigenic, but also dependent on non-genetic factors, thus a reliable mouse model is difficult to develop. Furthermore, while many GA mouse models have been identified, cleft palate is often seen in addition to other phenotypes. Homeobox and regulatory genes have been heavily implicated in developmental disorders and it is presumably, in part, due to random and unidentified mutations in these genes that cleft palate develops. Thus, while such studies add weight to the supposition that cleft palate has a complex aetiology, it adds little to in utero diagnosis or surgical correction of the disorder. Furthermore, there are severe animal welfare implications of studying cleft palate in mice, with GA offspring left unable to feed properly, or survive to point at which the underlying mechanisms of cleft deformation can be deciphered. The homozygous MSX-1 null mutant mouse, for instance lacks $M S X-1-$ a homeobox gene that is expressed in a number of developing organs in vertebrates - results in neonates failing to survive, because of severe craniofacial abnormalities (Satokata and Maas 1994). Thus, studying the aetiology of the disorder is almost impossible in the context of a complex mammalian species and in many respects monitoring general homeobox gene function in simpler organisms, such as nematode worms, might be significantly advantageous as the prelude to studies in mice.

Modelling human Down's syndrome (DS) in mice might be challenged on a similar basis. DS exists in three main forms that result in variable levels of mental retardation and physically evident features. The most common form results in an extra copy of chromosome 21 in all the cells of the affected individual's body (trisomy 21). Mosaic trisomy 21 is similar, except that the extra chromosome 21 is only present in some of the cells of the affected individual. The third form of DS is caused by translocational errors that result in repeats within chromosome 21. Trisomy (Ts) mouse models, including the naturally occurring Ts16 mouse model that carries an extra copy of mouse chromosome 16 (Epstein et al. 1985), were first described in the 1970s. However, since the human chromosome 21 and mouse chromosome 16 are not entirely syntenic and human and mouse chromosomal numbers and gene arrangements differ, it is not surprising that Ts16 mice display developmental cardiovascular defects that are not evident in human DS (Bacchus et al. 1987). The fact that Ts mice do not survive beyond birth, prohibits the study of CNS development and of the age-related diseases, such as AD, associated with DS. The Ts65Dn mouse carries an extra copy of the part of mouse chromosome 16 equivalent to the critical region of human chromosome 21 (Akeson et al. 2001). These mice survive to adulthood, and display some of the characteristics of human DS, including delayed postnatal development, muscular trembling, male sterility, skeletal malformations and abnormal cholinergic function but still do not develop AD (Holtzman et al. 1996, Hunter et al. 2004). Other attempts to create a mouse model of DS involved the addition of an almost entire copy of human chromosome 21 to the mouse genome, to give the Tc1 mosaic mouse (70) which more closely models mosaic trisomy 21 in humans in that these mice 
exhibit neurodegeneration and premature ageing. The prospects for treating DS are challenged on the basis of 1) the ethics of altering the genetic make-up of an individual 2) human rights-related issues, such as the right not to be discriminated against on the basis of being a DS sufferers 3) the lack of technology. Perhaps in view of these problems, focusing on the meeting the healthcare needs of DS patients would be a more prudent investment.

\section{CAN WE MODEL PSYCHIATRIC DISORDERS IN MICE?}

Attempts to model a number of psychiatric disorders in mice have been made. However, most models focus mutating or deleting single genes that have a tentative link to a psychiatric disorder. Indeed, with clear differences in the organisation of the mouse and human brains, the relevance of these models is far from certain. This entire field of research is very much in its infancy.

A prime example of this is the use of GA mouse models to understand the etiology of schizophrenia. Schizophrenia in humans is believed to be a multigenic, its development can be triggered by external factors and it can result in a variety of dysfunctional social behaviours. Relating the outcome of studies in GM mouse models has not been particularly successful for these reasons. Similarly, the failure of the NOTCH 3 gene knock-in mouse model for stroke and dementia syndrome (Lundkvist et al. 2004) to demonstrate clinical signs such as recurring strokes and dementia in adult patients could be attributed to differences in the spatial or temporal expression of species gene homologues, the organisation of the mouse and human brains or species longevity.

Depression affects a growing number of people and is one of the most prevalent illnesses in the world. It is also clear that whilst the first antidepressants were, in essence, a serendipitous find in the 1950s, many patients remain unresponsive or exhibit unacceptable side effects even to more refined treatments. Mice with knockout or site-specific mutations of single genes resulting in altered serotonergic, adrenergic, peptide, glutamate or immunological central nervous function have been developed (reviewed in Cryan and Mombereau 2004). A variety of behavioural tests (but note not tests that measure dependency) form part of the regulatory requirements for testing new psychoactive therapeutics. These are often tests conducted in mice in a piece meal fashion, and it is clear that some symptoms of human depression, such as weight changes, are much more easily modelled and measured in mice than other symptoms, such as suicidal tendencies. In fact, the high-profile withdrawals of and post-market restrictions place on a number of selective serotonin reuptake inhibitors highlight two major problems with mouse models: Firstly, Seroxat increases suicidal tendencies in adolescence but traditional mouse tests for signs of depression - such as the forced swim test - fail to pick this up. Secondly, other common side effects such as dependency and liver toxicity appear to be strain and age dependent and the outcome of preclinical studies, as in the case of Zelmid, can, therefore, be inconclusive.

\section{CARCINOGENICITY AND MUTAGENICITY TESTING}

A number of GA mouse models now exist for carcinogenicity testing, including the E $\mu-p i m-1$ transgenic mouse, the rasH2 transgenic mouse, the p53+/- heterozygous knock-out mouse, and the Tg.AC transgenic mouse. These models are often able to detect carcinogens much more sensitively than genotypically normal strains and, as a consequence, fewer mice might be required for each chemical than would ordinarily be required if genetically normal strains were used. For instance, the E $\mu$-pim-1 transgenic mouse, which contains the activated pim-1 oncogene, develops cancers when exposed to low levels of mild genotoxic carcinogens (Kroese et al. 1997) and the rasH2 transgenic mouse that carries a mutated p21 Ha-ras oncogene, displays enhanced susceptibility to neoplastic induction (MacDonald 2004). This often means that genotoxins and carcinogens can be identified in a shorter study time frame than by traditional assays (Yamamoto et al. 1996). Other models, such as the p53+/heterozygous knock-out mice (reviewed by Jacobson-Kram et al. 2004), are useful for detecting specific types of carcinogens whereas models such as the Tg.AC (that carries an activated v-Ha-ras oncogene fused to a mouse globin promoter) is suited to detecting topically applied chemicals that cause skin cancers. Although these models have yet to be formally accepted into the regulatory testing framework, the US Food and Drug Administration have suggested how several of these models could be used in this context.

Similarly, the Organisation for Economic Cooperation and Development (OECD) is considering the benefits of using the lacI BigBlue ${ }^{\mathrm{TM}}$ mouse and LacZ Muta ${ }^{\circledR}$ mouse transgenic models for mutagenicity testing (Wahnschaffe et al. 2005). The mutagenic target of Muta ${ }^{\circledR}$ mouse is a bacterial $\mathrm{LacZ}$ gene, and the target of Big Blue is the LacI repressor 
gene. Both $L a c Z$ and $L a c I$ serve as reporter genes: The LacI repressor binds to the lac operon and prevents the expression of $ß$-galactosidase from the LacZ gene. Hence, mutations in the LacI repressor gene result in changes in the levels of $ß$-galactosidase expression, whereas mutations in the $L a c Z$ gene result in the expression of mutated forms of the enzyme. This means that exposure to a mutagen is, in theory, results in mutations which can be detected by analysing ß-galactosidase activity by expressing the enzyme from DNA extracted from the tissues of exposed mice. Tests in these transgenic mice are not, however, able to detect mutagens that cause chromosomal aberrations. Hence, a strategy that takes into account the information which can be reasonably obtained by using ex vivo and cell-based assays should be applied before tests are conducted in mice, in order to minimise in vivo studies, whether or not they employ GA animals.

The incidence of cancer in humans is linked to the accumulation or induction of genetic damage or mutations or with dysfunctional DNA repair. Hence, the risk of cancer amplified with each round of cell division. This relationship is less obvious in laboratory mice with around $30 \%$ of mice developing cancers during their 2-3 year life-spans. One reason for this could be that mice are relatively deficient in antineoplastic defence mechanisms (Hanahan and Weinberg 2000), although higher metabolic rates in mice than in humans, and species differences in detoxification undoubtedly contribute to the higher frequency of cancers in mice than in humans. Furthermore, most human cancers arise in epithelial cell layers but this is not usually the case in mice. Models such as p53 mutant mice do, however, develop tumours that more closely resemble the epithelial cancers found in humans (Artandi et al. 2000), presumably because cells from these mice contain chromosomes with more similar telomeres to human telomeres, the latter of which appear to be more susceptible to end-to-end chromatid fusion and non-reciprocal translocation of chromatid DNA and the abnormal karyotypes common to human but not most mouse cancers (Artardi and Jacks 1999). Indeed, p53 +/- heterozygous mouse and transgenic have been used to establish a number of cancer models for drug development and cancer research.

\section{DISCUSSION}

There are strong arguments for and against the use of mouse models in medical research. Indeed, whereas some models have contributed significantly to the protection of human health, many other models have led to a false sense of hope for patients worldwide. In particular, the inability of many GA mouse models to recapitulate all the features of a human disease has often resulted in several mouse models being created for studies on different aspects of the disease in question, with the interpretation of the information from such studies confounded by differences in the genetic backgrounds of the mice used. This has potentially slowed, rather than expedited, the development of new medical treatments. Hence, there is a desperate need to formally validate or invalidate GA mouse models in very much the same way as is required for many non-animal methods used for regulatory testing.

GA mice might provide a more sensitive way of detecting chemical toxicants than genetically normal mice, reducing the number of animals needed per study. They may also provide a scientifically valid alternative to studies with severe consequences for the welfare of higher order laboratory mammals, such as non-human primates, for instance, where transgenic TgPVR 21 mice expressing the human polio virus receptor are used to neurovirulence test the oral polio vaccine (OPV; Dragunsky et al. 2003). In these instances, a case for using mouse models can be made on the basis of animal welfare. However, in some cases, decades of research in GA mice have failed to provide any tangible benefit to human health. The first knockout, transgenic and trisomy mice were all produced in the 1980s. These included HPRT (hypoxanthine-guanine phosphoribosyl transferase) knock-out mouse. HPRT gene mutations in humans have been associated with Lesch-Nyhan syndrome (LNS; Mansour et al. 1988). Despite the early link between the gene and the corresponding human disease, only some of the symptoms of the disease can be treated and there is currently no specific treatment for the neurological symptoms of LNS. Similarly, the first transgenic mouse contained a mutated form of the metallothionein-1 (MT-1) gene homologous to the human gene associated with Menkes disease (Cox and Palmiter 1892) but despite over 20 years of research, the main way of managing this disease is using copper supplements. Equally, in the case of disorders such as cleft palate and DS, although GA mouse models have permitted some of the features of the diseases to be studied, it is not clear whether this will assist with the management or prevention of the diseases themselves.

\section{REFERENCES}

Ablamunits V, Elias D, Reshef T, Cohen IR: Islet T cells secreting IFN-gamma in NOD mouse 
diabetes: arrest by p277 peptide treatment. J. Autoimmun. 11:73-81, 1998.

Akeson EC, Lambert JP, Narayanswami S, Gardiner K, Bechtel LJ, Davisson MT: Ts65Dnlocalization of the translocation breakpoint and trisomic gene content in a mouse model for Down syndrome. Cytogenet. Cell Genet. 93:270-276, 2001.

Ameen N, Alexis J, Salas P: Cellular localisation of the cystic fibrosis transmembrane conductance regulator in mouse intestinal tract. Histochem. Cell Biol. 114:69-75, 2000.

Artandi SE, Chang S, Lee SL, Alson S, Gottlieb GJ, Chin L, DePinho RA: Telomere dysfunction promotes non-reciprocal translocations and epithelial cancers in mice. Nature 406:641-645, 2000.

Attardi LD, Jacks T: The role of p53 in tumour suppression: lessons from mouse models. Cell. Mol. Life Sci. 55:48-63, 1999.

Ayash-Rashkovsky M, Bentwich Z, Arditti F, Friedman S, Reisner Y, Borkow G: A novel small animal model for HIV-1 infection. FASEB J.19: 1149-1151, 2005.

Bacchus C, Sterz H, Buselmaier W, Sahai S, Winking $\mathrm{H}$ : Genesis and systematization of cardiovascular anomalies and analysis of skeletal malformations in murine trisomy 16 and 19: Two animal models for human trisomies. Hum. Genet. 77:12-22, 1987.

Boot HJ, Kasteel DTJ, Buisman A-M, Kimman TG: Excretion of wild-type and vaccine-derived poliovirus in the faeces of poliovirus receptor-transgenic mice. J. Virol. 77:6541-6545, 2003.

Chang LJ, Zhang C: Infection of replication of Tathuman immunodeficiency viruses: Genetic analyses of LTR and tat mutations in primary and long-term human lymphoid cells. Virology 211:157-169, 1995.

Cox DR, Palmiter RD: Assignment of the mouse metallothionein-1 gene to chromosome-8: Implications for human Menkes disease. Clin. Res. 30:A117-A117, 1982.

Cryan JF, Mombereau C: In search of a depressed mouse: utility of models for studying depression-related behaviour in genetically modified mice. Mol. Psychiatry 9:326-357, 2004.

Daingain J, Vrbova G: Muscle development in $m d x$ GA mice. Muscle Nerve 7: 700 - 704, 1984.

Dalke C, Graw J: Mouse mutants as models for congenital retinal disorders. Exp. Eye Res. 81: 503 - 512, 2005.

Dragunsky E, Nomura T, Karpinski K, Furesz J, Wood DJ, Perivikov Y, Abe S, Kurata T,
Vanloocke O, Karganova G, Taffs R, Heath A et al.: Transgenic mice as an alternative to monkeys for neurovirulence testing of live oral poliovirus vaccine: Validation by a WHO collaborative study. Bull. World Health Org. 81:251-262, 2003.

ElAmraoui A, Sahly I, Picaud S, Sahel J, Abitbol M, Petit C: Human Usher 1B mouse shaker-1: The retinal phenotype discrepancy explained by the presence/absence of myosin VIIA in the photoreceptor cells. Hum. Mol. Genet. 5:1171-1178, 1996.

Elias D, Meilin A, Ablamunits V, Birk OS, Carmi P, Könen-Waisman S, Cohen IR: Hsp60 peptide therapy of NOD mouse diabetes induces a Th2 cytokine burst and downregulates autoimmunity to various ß-cell antigens. Diabetes 46:758-764, 1997.

Epstein CJ, Cox DR, Epstein LB: Mouse trisomy 16: An animal model of human trisomy 21 (Down syndrome). Ann. N. Y. Acad. Sci. 450:157-168, 1985.

Fletcher S, Honeyman K, Fall AM, Harding PL, Johnsen RD, Steinhaus JP, Moulton HM, Iversen PL, Wilton SD: Morpholino oligomer-mediated exon skipping averts the onset of dystrophic pathology in the $m d x$ mouse. Mol. Ther. 15:1587-1592, 2007.

Gardner KL, Kearney JA, Edwards JD, Rafael-Fortney JA: Restoration of all dystrophin protein interactions by functional domains in trans does not rescue dystrophy. Gene Ther. 13:744-751, 2006.

Gibson F, Walsh J, Mburu P, Varela A, Brown KA, Antonio M, Beisel KW, Steel KP, Brown SD: A type VII myosin encoded by the mouse deafness gene shaker-1. Nature 374:62-64, 1995.

Gotz J, Chen F, van-Dorpe J, Nitsch RM: Tau filament formation in transgenic mice expressing P301L tau. J. Biol. Chem. 276:529-534, 2001.

Greaves DR, Fraser P, Vidal MA, Hedges M, Ropers D, Luzzatto L, Grosveld F: A transgenic mouse model of sickle cell disorder. Nature 11:183-185, 1990.

Hanahan D, Weinberg RA: The hallmarks of cancer. Cell 100:57-70, 2000.

Hanna J, Wernig M, Markoulaki S, Sun C-W, Meissner A, Cassady JP, Beard C, Brambrink T, Wu L-C, Townes TM, Jaenisch R: Treatment of sickle cell anemia mouse model with iPS cells generated from autologous skin. Science 318:1920-1923, 2007.

Hiota C, Larsson O, Shelton KD, Shiota M, Efanov AM, Hoy M, Lindner J, Kooptiwut S, Juntti-Berggren L, Gromada J, Berggren P-O, Magnuson MA: Sulfonylurea receptor type 1 
knock-out mice have intact feeding-stimulated insulin secretion despite marked impairment in their response to glucose. J. Biol. Chem. 277:37176-37183, 2002.

Holcomb L, Gordon MN, McGowan E, Yu X, Benkovic S, Jantzen P, Wright K, Saad I, Mueller R, Morgan D, Sanders S, Zehr C, O' Campo K, Hardy J, Prada C-M, Eckman C, Younkin S, Hsiao K, Duff K: Accelerated Alzheimer-type phenotype in transgenic mice carrying both mutant amyloid precursor protein and presenelin 1 transgenes. Nat. Med. 4:97-100, 1998.

Holtzman DM, Santucci D, Kilbridge J, Chua-Couzens J, Fontana DJ, Daniels SE, Johnson RM, Chen K, Sun Y, Carlson E, Alleva E, Epstein CJ, Mobley WC: Developmental abnormalities and age-related neurodegeneration in a mouse model of Down syndrome. Proc. Natl. Acad. Sci. U.S.A. 93:13333-13338, 1996.

Hunter CL, Bimonte-Nelson HA, Nelson M, Eckman CB, Granholm A-C: Behavioral and neurobiological markers of Alzheimer's disease in Ts65Dn mice: effects of estrogen. Neurobiol. Aging 25:873-884, 2004.

International Human Genome Sequencing Consortium: Initial sequencing and analysis of the human genome. Nature 409:860-921, 2001.

Jacobs GH, Neitz J, Deegan JF: Retinal receptors in rodents maximally sensitive to ultraviolet light. Nature 353:655-656, 1991.

Jacobson-Kram D, Sistare FD, Jacobs AC: Use of transgenic mice in carcinogenicity hazard assessment. Toxicol. Pathol. 32 (Suppl.1):49-52, 2004.

Jenkins ES, Combes RD: The welfare problems associated with using transgenic mice to bioassay for bovine spongiform encephalopathy. Anim. Welf. 8:421-431, 1999.

Kanezaki Y, Obata T, Matsushima R, Minami A, Yuasa T, Kishi K, Bando Y, Uehara H, Izumi K, Mitani T, Matsumoto M, Takeshita Y et al.: $\mathrm{K}_{\text {АTP }}$ channel knockout mice crossbred with transgenic mice expressing a dominant negative form of human insulin receptor have glucose intolerance but not diabetes. Endocr. J. 51:133-144, 2004.

Kerem B, Rommens JM, Buchanan JA, Markiewicz D, Cox TK, Chakravarti A, Buchwald M, Tsui LC: Identification of the cystic fibrosis gene: genetic analysis. Science 245:1073-1080, 1989.

Kroese ED, van Steeg H, van Oostrom CT, Dortant PM, Wester P, van Kranen HJ, de Aries A, van Kreijl CF: Use of E-pim transgenic mice for short-term in vivo carcinogenicity testing: Iymphoma induction by benzo[a]pyrene but not
TPA. Carcinogenesis 19:975-908, 1997.

Kunzelmann K, Schreiber R, König J, Mall M: Ion transport induced by proteinase-activated receptors (PAR2) in colon and airways. Cell Biochem. Biophys. 36:209-214, 2002.

Lundkvist J, Zhu S, Hansson EM, Schweinhardt P, Qing M, Beatus P, Dannaeus K, Karlstrom H, Johansson CB, Viitanen M, Rozell B, Spenger C, Mohammed A, Kalimo H, Lendahl U: Mice carrying a R142C Notch 3 knock-in mutation do not develop a CADASIL-like phenotype. Genesis 41:13-22, 2004.

MacDonald JS: Human Carcinogenic Risk Evaluation, Part IV: Assessment of human risk of cancer from chemical exposure using a global weight-of-evidence approach. Toxicol. Sci. 82:3-8, 2004.

MacLaren RE, Pearson RA, MacNeil A, Douglas RH, Salt TE, Akimoto M, Swaroop A, Sowden JC, Ali RR: Retinal repair by transplantation of photoreceptor precursors. Nature 444:203-207, 2006.

Mall M, Grubb BR, Harkema JR, O'Neal WK, Boucher RC: Increased airway epithelial $\mathrm{Na}^{+}$ absorption produces cystic fibrosis-like lung disease in mice. Nat. Med. 10:487-493, 2004.

Manci EA, Hilliery CA, Bodian CA, Zhang ZG, Lutty GA, Coller BS: Pathology of Berkeley sickle cell mice: similarities and differences with human sickle cell disease. Blood 107:1651-1658, 2006.

Mansour SL, Thomas KR, Capecchi MR: Disruption of the proto-oncogene int-2 in mouse embryo-derived stem cells: a general strategy for targeting mutations to non-selectable genes. Nature 336:348-352, 1988.

Meuleman P, Libbrecht L, De Vos R, de Hemptinne B, Gevaert K, Vandekerckhove J, Roskams T, Leroux-Roels G: Infection by proxy: The role of chimeric mice in HBV and HCV research. Morphological and biochemical characterization of a human liver in a uPASCID mouse chimera. Hepatology 41:847-856, 2005.

Mouse Genome Sequencing Consortium: Initial sequencing and comparative analysis of the mouse genome. Nature 420:520-562, 2002.

O'Doherty A, Ruf S, Mulligan C, Hildreth V, Errington ML, Cooke S, Sesay A, Modino S, Vanes L, Hernandez D, Linehan JM, Sharpe PT et al.: An aneuploid mouse strain carrying human chromosome 21 with Down syndrome phenotypes. Science 309:2033-2037, 2005.

Paszty C, Brion CM, Manci E, Witowska HE, Stevens ME, Mohandas N, Rubin EM: Transgenic knockout mice with exclusively human sickle haemoglobin and sickle cell 
disease. Science 278:876-878, 1997.

Rozmahel E, Gyomorey K, Plyte S, Nguyen V, Wilschanski M, Durie P, Bear CE, Tsui LC: Incomplete rescue of cystic fibrosis transmembrane conductance regulator deficient mice by the human CFTR cDNA. Hum. Mol. Genet. 6:1153-1162, 1997.

Satokata I, Maas R: Msx-1 deficient mice exhibit cleft palate and abnormalities of craniofacial and tooth development. Nat. Genet. 6:348-356, 1994.

Shichor T, Crawford M, Engelhardt T, Bell G, Bell D, Carmichael FJL, Kim PCW: HRC 101 improves survival during hypoxia in SAD mice. Can. J. Anesth. 54:44491, 2007.

Sung C-H, Makino C, Baylor D, Nathans J: A rhodopsin gene mutation responsible for autosomal dominant retinitis pigmentosa results in a protein that is defective in localization to the photoreceptor outer segment. J. Neurosci. 14:5818-5833, 1994.

Trudel M, Saadane N, Garel MC, Bardakdjian-Michau J, Blouquit Y, Guerquin-Kern JL, Rouyer-Fessard P, Vidaud D, Pachnis A, Romeo PH, Beuzard Y, Costantini F:
Towards a transgenic mouse model of sickle cell disease - Hemoglobin SAD. EMBO J. 10:3157-3165, 1991.

Wahnschaffe U, Bitsch A, Kielhorn J, Mangelsdorf I: Mutagenicity testing with transgenic mice. Part I: Comparison with the mouse bone marrow micronucleus test. J. Carcinog. 4: 3, 2005. doi: 10.1186/1477-3163-4-3

Wicker LS, Clark J, Fraser HI, Garner VES, Gonzalez-Munoz A, Healy B, Howlett S, Hunter K, Rainbow D, Rosa RL, Smink LJ, Todd JA et al.: Type 1 diabetes genes and pathways shared by humans and NOD mice. J. Autoimmun. 25:29-33, 2005.

Yamamoto S, Mitsumori K, Kodama Y, Matsunuma N, Manabe S, Okamiya H, Suzuki H, Fukuda T, Sakamaki Y, Sunaga M, Nomura G, Hioki K et al.: Rapid induction of more malignant tumors by various genotoxic carcinogens in transgenic mice harboring a human prototype c-Ha-ras gene than in control non-transgenic mice. Carcinogenesis 17:2455-2461, 1996. 